\title{
Análisis de la integración del Big Data en los programas de contaduría pública en universidades acreditadas en Colombia
}

Analysis of the integration of big data into public accounting programs at accredited universities in Colombia

\author{
Julián Andrés Mayor-Ríos \\ Magíster en Ingeniería Administrativa, Universidad Nacional de Colombia, \\ Medellín - Colombia, jamayorr@gmail.com \\ Diana Milena Pacheco-Ortiz \\ Magíster en Enseñanza de las Matemáticas, Instituto Tecnológico Metropolitano, \\ Medellín-Colombia, dianapacheco@itm.edu.co \\ Juan Camilo Patiño-Vanegas \\ PhD. (c) en Pensamiento Complejo, Multiversidad Mundo Real Edgar Morín, \\ Ciudad de México- México, camilop3@hotmail.com \\ Santiago Ernesto Ramos-y-Yovera \\ Magíster en Finanzas y Negocios Internacionales, Universidad Nacional José Faustino Sánchez \\ Carrion, Lima - Perú, sramos@unjfsc.edu.pe
}

\begin{abstract}
Cómo citar / How to cite
Mayor-Ríos, J. A., Pacheco-Ortiz, D. M., Patiño-Vanegas, J. C. \& Ramos-y-Yovera, S. E. (2019). Análisis de la integración del Big Data en los programas de contaduría pública en universidades acreditadas en Colombia. Revista CEA, 5(9), 53-76. https://doi.org/10.22430/24223182.1256
\end{abstract}

Recibido: 12 de junio de 2018

Aceptado: 21 de diciembre de 2018

\section{Resumen}

La profesión contable tiene como reto clave desarrollar habilidades en el Big Data; aspecto fundamental para proponer ideas innovadoras con base a los datos. Por ello, llama a reflexionar a los programas de contaduría pública, la incorporación en los planes de estudio el tema relacionado con el Big Data. El objetivo del artículo fue presentar los resultados de un análisis sobre la incorporación del Big Data en los programas de contaduría pública en las universidades acreditadas de Colombia. La metodología aplicada consistió en explorar a través de datos secundarios los planes de estudio de 29 universidades, para identificar la relación directa con el Big Data.

Entre los resultados se observó que la revolución de los datos se ha masificado haciéndose viral en la sociedad e importante para las universidades, ellas desarrollan competencias básicas que permiten a los profesionales en contabilidad, administrar y gestionar los datos de manera superficial. Sin 
embargo, aún no logran incorporar herramientas especializadas de Big Data para procesar datos no estructurados, lo que las obliga a articular los planes de estudio con las nuevas tendencias tecnológicas.

Palabras clave: Big Data, tecnología de la información, sistemas de información, educación contable.

\section{Abstract}

Accounting professionals face the challenge of developing big data skills, which are essential to propose innovative ideas based on large amounts of information. As a result, public accounting programs should consider the incorporation of big data into their study plans. This paper presents the results of an analysis of the integration of big data into public accounting programs at accredited universities in Colombia. The method was an exploration of secondary data about study plans at 29 different universities to identify direct relationships with the field of big data.

The results show that the data revolution has become widely adopted, viral in society, and important for universities, where accounting professionals develop basic competencies to administer and manage data in a superficial manner. Although higher education institutions have not introduced specialized big data tools to process unstructured data, now they must articulate their study plans with new technology trends.

Keywords: big data, information technology, information systems, accounting education.

\section{INTRODUCCIÓN}

En las últimas décadas ha incrementado el avance de nuevas tecnologías. Desde 1980 la "revolución informática» dispuso el PC al alcance de la sociedad; en la década de 1990, "la revolución del internet» conectó a todo el planeta a la web y trajo la «revolución Web 2.0 »; y en pleno siglo XXI, el surgimiento de una «revolución de los datos» por la masificación de dispositivos conectados a la red (O’Brien, 2015; Sáinz, Iñigo, Raquel \& Sanz, 2013).

Frente a esto, el análisis de los datos y de negocios son disciplinas antiguas que han experimentado notables crecimientos en todos los campos del saber, particularmente en organizaciones y empresas, por la necesidad de disponer de herramientas que analicen datos y que estos sirvan para toma de decisiones eficaces y eficientes (Malvicino \& Yoguel, 2016). Como consecuencia de esto, en los últimos años ha surgido el término 'Big Data' (Maté, 2014) conocido como "minería de datos», un campo de las ciencias de la computación que intenta descubrir patrones en grandes volúmenes de datos. Adicionalmente, es definida como la capacidad que tiene la sociedad para dar un valor significado a los datos, con el fin de conseguir beneficios (Mayer-Schomberger \& Cukier, 2013; Sáinz et al., 2013). Del mismo modo, Gartner (2018) lo relaciona como una gran variedad de activos de información que demandan formas de conocimiento rentables e innovadoras para la toma de decisiones y automatización de procesos. Otros indican que son el conjunto de datos, cuyo tamaño excede la capacidad de las herramientas de software para capturar, almacenar, gestionar y analizar (Joyanes, 2013). 
Este término es bastante nuevo y la razón de su popularidad es la cantidad de información generada por las diferentes disciplinas científicas, a través de la masificación y utilización de las tecnologías de información y comunicaciones (Malvicino \& Yoguel, 2016; Vasarhelyi, Kogan, \& Tuttle, 2015). Sin embargo, no es el tamaño de los datos lo que cuenta, sino las ideas que se pueden proponer o extraer para predecir tendencias, crear oportunidades y generar ventajas competitivas (Huerta \& Jensen, 2017; Maté, 2014); Lo que significa que el Big Data estaría provocando cambios en las organizaciones, estimulando el trabajo, aumentando el acceso a nuevos mercados y fortaleciendo la toma de decisiones (Malvicino \& Yoguel, 2016).

Al respecto, esta tecnología va tomando fuerza e interés entre diferentes sectores, como salud, educación, ciudades, movilidad, retail, manufacturero, entre otros (Goyzueta, 2015). En este mismo sentido, la empresa MGI, que tiene como objetivo realizar estudios mundiales para comprender la evolución de la economía mundial, indicó que los sectores como ventas y marketing, manufacturero, salud, smart cities y en especial los servicios financieros son los sectores de la industria que más se pueden beneficiar de esta tecnología (McKinsey \& Company, 2011).

La International Federation of Accountants (IFAC, 2018) afirma que la profesión contable también está cambiando y desarrollándose como resultado de la digitalización y los avances tecnológicos. También, en los próximos años muchas de las transacciones realizadas por los contadores se realizarán mediante inteligencia artificial y sistemas de automatización. Lo que significa que, en los próximos años, los dueños de negocios comenzarán a buscar contadores con mejores habilidades tecnológicas. Por lo tanto, habrá una tendencia creciente para la profesión contable (Gamage, 2016).

Del mismo modo, la Association of Chartered Certified Accountants (2013) manifiesta que los profesionales de las finanzas, contaduría, estadística, necesitarán encontrar la forma de utilizar Big data para medir el desempeño organizacional, gestión del riesgo de inversión, la valoración de los activos y la toma de decisiones y consideran que en los próximos años habrá más transacciones de datos analizados por contadores, en lugar de analistas de datos.

Por ello, estas nuevas tendencias llaman a reflexionar sobre el rol del profesional contable y los retos a los que se deben enfrentar, haciendo necesario desarrollar un pensamiento analítico, la adaptación a la digitalización, habilidades y competencias que permitan darle sentido a los datos, crear soluciones a partir de ellas y proponer ideas innovadoras para las organizaciones (IFAC, 2018; Vasarhelyi et al., 2015). Es así como, el mayor reto para la inversión en Big Data, será disponer de personas adecuadas y formadas para convertir la acumulación de los datos en decisiones estratégicas (Puyol, 2014).

Esto crea importantes retos para los contadores, y, por ende, las instituciones de educación superior deben tomar decisiones de cambio, en consideración al acelerado desarrollo de la ciencia y la tecnología (Patiño \& Santos, 2009). Además, como lo sugiere la American Acounting Association (AAA, 2012). La incorporación en los planes de estudio de contaduría debe transformase hacia nuevas habilidades en Big Data y tendencias tecnologías que van a cambiar el futuro. Así como garantizar a los estudiantes nuevos conocimientos y competencias para una inserción laboral que respalden a organizaciones más eficientes y competitivas (Janvrin \& Watson, 2017). 
Es por ello que, Sledgianowski, Gomaa, \& Tan (2017) manifiestan que cada vez más instituciones integran el Big Data en los cursos de contabilidad para proporcionar a los estudiantes las habilidades y los conocimientos necesarios para extraer de los datos el valor necesario que necesitan las organizaciones, cerrando la brecha entre las necesidades del negocio y las tecnologías de la información. A su vez, Janvrin \& Watson (2017) recomienda un plan de estudios de contabilidad integrado e interdisciplinario que exponga a los estudiantes no solo a los conceptos de estadísticas, administración de datos y análisis, sino también al uso práctico de herramientas apropiadas para Big Data.

Por lo tanto, el objetivo que tiene este artículo es explorar en los programas de contaduría pública de universidades acreditadas en Colombia para analizar si los planes de estudio incorporan temas de Big Data. Sin embargo, esta aproximación no pretende profundizar al nivel de metodología de cada universidad, si no dar una mirada conceptual y contrastar si las instituciones incorporan estas competencias expresadas en el perfil profesional.

\section{MARCO TEÓRICO}

Para tener una idea general y detallada de lo que es Big Data, primero hay que dar una mirada a lo que son datos y donde están. Los datos están en todas partes: en el aire, en el agua, en la luz, en las plantas, en la televisión, en la web y en los seres humanos, quienes generan cantidad de información asociada al comportamiento, lo que frecuentan, lo que compran, los que les gusta y lo que no. Además, los datos se clasifican en tres categorías: estructurados, como aquello que está en formato y se producen en un orden especifico (fecha de nacimiento DD, MM, AA, documentos entre otros); no estructurados, como aquello que se representa en audio, video, fotografía, PDF, Word; y semi estructurados (archivos HTML, XML) (Joyanes, 2013; Puyol, 2014; Sáinz et al., 2013).

Por tanto, investigaciones realizadas indican que el Big Data se trata del crecimiento de los datos no estructurados en los últimos años (Strong et al., 2015) donde el reto será interpretarlos para que sean perceptibles y entendibles, y la manera de hacerlo es a través de los denominado sensores, que son dispositivos y/o herramientas de software que tienen por objetivo capturarlos, procesarlos y transformarlos para tomar decisiones (Martínez-Martínez \& Lara-Navarra, 2014; Molina, 2002), tal como lo menciona Strong et al, (2015): «La información es poder y se gestiona correctamente a través del Big Data puede proporcionar una cantidad de conocimiento».

Por tal motivo, varios denominan el Big Data como tecnología estratégica, considerando que la esencia no está en el número sino la manera como se pueden aprovechar para generar oportunidades de negocio (Assunção, Calheiros, Bianchi, Netto, \& Buyya, 2014; Joyanes, 2013; Vasarhelyi et al., 2015).

Casi desde su concepción, se consideró el uso de Big Data para almacenar y analizar datos estructurados. Google fue el primero en implementar una tecnología con tal fin: Bigtable. Que en un principio se utilizó para almacenar datos de los proyectos Google Earth y Google Finance (Puyol, 2014) 
Por consiguiente, empresas de algunos países, como Estados Unidos, reconocen que incorporar el Big Data en las actividades empresariales promueven de manera eficiente tareas como la toma de decisiones, creación de nuevos productos y servicios, alcanzando una productividad entre el $5 \%$ y 6 $\%$ superior a la que se esperaba considerando otras inversiones y usos tecnológicos (Strong et al., 2015). De la misma manera, Malvicino \& Yoguel (2016) afirman que esta tecnología puede generar un impacto positivo que beneficie al sector público y privado en el aumento de la productividad y competitividad.

Por otro lado, los desarrollos tecnológicos que han acelerado el crecimiento de los datos de manera exponencial en los últimos años han sido, especialmente, por las redes sociales, el internet, el internet de las cosas, entre otros (Saggi \& Jain, 2018). Frente a esto, varios estudios estadísticos sobre el crecimiento de los datos describen que la información digital en el año 2007 de todo el mundo fue más de 276.000 millones de gigabytes, unas 13.800 veces la información almacenada veinte años atrás y se prevé que la información generada en 2020 será cincuenta veces la generada en el 2011 (Gantz \& Reinsel, 2012; McKinsey \& Company, 2011; Sáinz et al., 2013). Otros estudios indican que las organizaciones recopilaron más datos durante los años 2016 y 2017 en comparación con 2000 años atrás (Warren, Moffitt y Byrnes 2015). Sin embargo, esto no significa que el mundo este sumergido en más información que en otro momento, sino que esa información está aumentando de manera significativa (Mayer-Schomberger \& Cukier, 2013).

El enfoque que dan las empresas al Big Data puede variar en tres dimensiones, denominas 3v: volumen, variedad, variabilidad (IDC \& Curto, 2012; Joyanes, 2013).

Volumen: hace referencia a la cantidad de datos que las empresas deben aprovechar para tomar decisiones. Siendo la característica que más se asocia al Big Data.

Variedad: a medida que se multiplican los canales de interacción con clientes, empleados, proveedores y procesos de negocio, la información de valor es cada vez más el resultado de la combinación de datos de múltiple origen y tipología que puede estar en forma estructurada, semiestructurada o no estructurada.

Velocidad: aunque los ciclos de negocio se han acelerado, no todos los datos de una organización tienen la misma urgencia de análisis asociada. La clave para entender en qué punto del espectro de la velocidad es necesario trabajar (desde el procesado en lote hasta el flujo de datos continuo) está asociada a los requerimientos de los procesos y los usuarios.

Valor: en el contexto de Big Data, valor hace referencia a los beneficios que se desprenden del uso de Big Data (reducción de costes, eficiencia operativa, mejoras de negocio).

Adicionalmente, Puyol (2014) agrega la veracidad como otro enfoque, haciendo alusión al nivel de fiabilidad para conseguir alta calidad de los datos, como un requisito importante y un reto fundamental de Big Data para disminuir el nivel de incertidumbre que surge a medida que las empresas intentan comprender mejor el mundo incierto que les rodea.

Frente a lo anterior, surge el data mining o minería de datos como la técnica utilizada en el Big Data para ayudar a comprender el contenido de una base datos, en un proceso analítico de exploración para descubrir patrones consistentes implícitos o relaciones sistemáticas (Báez, 2015). Lo que hace 
Análisis de la integración del Big Data en los programas de contaduría pública en universidades acreditadas en Colombia

la minería de datos es reunir las ventajas de varias disciplinas como la estadística, la inteligencia artificial, la computación, las bases de datos y el procesamiento masivo, especialmente usando como materia prima las bases de datos.

Tiene tres objetivos principales: descripción, predicción y prescripción. El análisis descriptivo se centra en encontrar patrones y tendencia de los datos haciéndolo interpretables por los humanos (Amani \& Fadlalla, 2017); en cuanto al análisis predictivo, se enfoca en lo que podría suceder una vez se interpreten los datos, mediante cálculos de probables eventos futuros, aplicando modelos predictivos y de probabilidad, pronósticos y análisis estadístico (Appelbaum, Kogan, Vasarhelyi, \& Yan, 2017). En cuanto al análisis prescriptivo, se centra en proporcionar la mejor solución para el problema dado (Amani \& Fadlalla, 2017).

Sin embargo, existe una amplia variedad de técnicas de minería de datos, como redes neuronales artificiales (NN), razonamiento basado en casos (CBR), algoritmos genéticos (GA), árboles de decisión (DT), reglas de asociación (AR), máquinas de vectores de soporte (SVM), regresión, mapas auto organizados (SOM), análisis difuso, entre otros (Amani \& Fadlalla, 2017).

Así, las técnicas de la minería de datos se han aplicado a diferentes entornos; la educación, gobierno, empresas, en clubes deportivos, las relaciones con los clientes, la inteligencia de negocios, estudios bibliométricos y en un escenario reciente a los sistemas contables y financieros para determinar detención de posibles fallas en los sistemas contables (Báez, 2015), tal como se puede ver en la Tabla 1.

Tabla 1. Aplicaciones de minería de datos en temas de contabilidad

Table 1. Applications of data mining in different accounting fields

\begin{tabular}{|c|c|}
\hline $\begin{array}{l}\text { Aplicación de minería de datos en } \\
\text { contabilidad }\end{array}$ & $\begin{array}{l}\text { Sub-tema de aplicación de minería de datos en } \\
\text { contabilidad }\end{array}$ \\
\hline \multirow[t]{5}{*}{ Contabilidad financiera (11\%) } & Conceptos de contabilidad \\
\hline & Calidad de datos contables \\
\hline & Estándares de contabilidad \\
\hline & Análisis financiero \\
\hline & Desempeño financiero \\
\hline \multirow[t]{3}{*}{ Contabilidad gerencial (25 \%) } & Administración de activos \\
\hline & Administración de costos \\
\hline & Presupuestos \\
\hline \multirow[t]{4}{*}{ Conformidad y aseguramiento (64 \%) } & Auditoría \\
\hline & Salud de negocios \\
\hline & Contabilidad forense \\
\hline & Cumplimiento de impuestos \\
\hline
\end{tabular}

Fuente: (Amani \& Fadlalla, 2017).

En menor porcentaje se puede aplicar a la contabilidad financiera enfocada en la calidad de los datos, estándares de contabilidad y desempeño financiero, asociados al control y aseguramiento de la información. Tal como lo manifiesta Báez (2015), la veracidad de la información minimiza en mayor medida las posibles fallas y riesgos en los sistemas contables. Adicionalmente, se puede aplicar a las actividades gerenciales como control de activos, costos y presupuestos. 
Por otro lado, y en mayor porcentaje, la aplicación de minería de datos se enfoca en el aseguramiento de la información. Probablemente esto ocurra porque a medida que los sistemas aumentan de tamaño y complejidad habrá pocas posibilidades de salvaguardar la seguridad de la información de forma manual, aumentando la posibilidad que la minería de datos juegue un papel fundamental para garantizar procesos más automatizados en la gestión empresarial y en auditorías que determinen que es importante para el inversionista (Chang et al., 2008; Gepp, Linnenluecke, O'Neill, \& Smith, 2018; Vasarhelyi et al., 2015). Así mismo, la Federación Internacional de Contadores (IFAC, 2018) manifiesta que la gestión de los datos son claves para todos los sectores económicos y en especial para el caso de la actividades financieras y contables.

Según Chamorro (2016), la profesión contable toma relevancia para las organizaciones, dado que asocia tanto temas administrativos y financieros, como la relación entre la responsabilidad social, ambiental y sostenibilidad. Además, se plantean fuertes desafíos gracias a la diversidad de los datos a considerar, por un lado, la mayoría de las empresas mantienen sus datos de informes financieros en bases de datos estructuradas y los informes de los estados financieros se presentan a los inversores de manera no estructurada. También, el volumen de los datos a auditar debe ser una actividad que garantice la transparencia de la (Financial Reporting Council (FRC, 2013), así mismo, la importancia de apropiar las capacidades técnicas en esta área para determinar patrones y características en los datos estructurados, semi estructurados y no estructurados (The association of Accountants and financial Professionals in Business (ACCA, 2012).

Adicionalmente, la Federación Internacional de Contadores (IFAC, 2018), indica que las habilidades en nuevas tecnologías de análisis de datos mejorarán la capacidad de los contadores para usar y administrar la tecnología.

Basado en lo anterior, las universidades acreditadas en Colombia están haciendo un esfuerzo por mejorar la calidad para comprometer el desarrollo curricular que propenden para una formación integral. La acreditación significa, que, con la opinión y la mirada de expertos externos, se puede dar fe pública sobre el cumplimiento de la calidad, la idoneidad y la solidez institucional para aportar al desarrollo económico, social, cultural, tecnológico y ambiental. Favoreciendo el reconocimiento nacional e internacional de una institución educativa (Consejo Nacional de Acreditación, 2015). En este caso, el Consejo Nacional de Acreditación (CNA), bajo su naturaleza académica, es el ente regulador que garantiza a la sociedad colombiana que las instituciones que hacen parte del sistema cumplen los más altos requisitos de calidad que realizan sus propósitos y objetivo.

Para describir las características que deben seguir las universidades acreditadas en Colombia, se referencia la resolución 3459 de 2003, constituida como una medida de desarrollo para el fortalecimiento de los programas de formación profesional de pregrado en Contaduría. Frente a esto, en la Tabla 2 se relacionan los requisitos que se deben contemplar en un plan de estudios, lo cual asocia tres áreas fundamentales: áreas de formación básica, área de formación profesional y área de formación socio económica.

Tabla 2. Plan de estudio básico programas contaduría pública en Colombia

Table 2. Basic study plan of public accounting programs in Colombia 
Análisis de la integración del Big Data en los programas de contaduría pública en universidades acreditadas en Colombia

\begin{tabular}{|c|c|c|c|c|c|}
\hline $\begin{array}{l}\text { Área de } \\
\text { formación }\end{array}$ & Cursos & $\begin{array}{c}\text { Área de } \\
\text { formación }\end{array}$ & Cursos & $\begin{array}{l}\text { Área de } \\
\text { formación }\end{array}$ & Cursos \\
\hline \multirow[t]{5}{*}{ Básica } & Matemáticas & Profesional & $\begin{array}{l}\text { Ciencias } \\
\text { contables y } \\
\text { financieras }\end{array}$ & Humanística & Ética y valores \\
\hline & Estadística & & $\begin{array}{l}\text { Formación } \\
\text { organizacional }\end{array}$ & & $\begin{array}{l}\text { Responsabilidad } \\
\text { social }\end{array}$ \\
\hline & Economía & & Información & & \\
\hline & Ciencias jurídicas & & Regulación & & \\
\hline & $\begin{array}{l}\text { Ciencias } \\
\text { administrativas }\end{array}$ & & & & \\
\hline
\end{tabular}

Fuente: (Ministerio de Educación Nacional, 2003).

De lo anterior, el área de formación básica está fundamentada en cinco componentes (matemáticas, estadística, economía, ciencias jurídicas, ciencias administrativas); lo cual se constituye en que el estudiante comprenda de manera crítica y comprensiva los principios básicos de la contaduría pública. En cuanto al área de formación profesional, se relacionan componentes de conocimiento práctico, orientado a formar al estudiante en herramientas y técnicas que le permitan reconocer que las organizaciones se comportan como sistemas dinámicos, en ambientes complejos y que es necesario interpretarlas para diseñar mecanismos de competitividad. Sin embargo, para el logro de esta formación, se puntualiza en el componente de información como aquella que se debe desarrollar hacia la construcción de las habilidades necesarias que debe tener el estudiante para que, a partir de los datos que se produce en una organización, se analicen y se transformen en conocimiento para tomar decisiones.

Basado en lo anterior, puede significar para las universidades en Colombia, la incorporación del manejo de los sistemas de información en el currículo de contaduría pública como un eje fundamental. Por otro lado, el área de formación socio humanística, se enfoca en los valores y principios que debe contemplar un contador público para trabajar de manera transparente e interdisciplinariamente con profesionales de otras ramas.

Otros autores proponen un marco de integración de competencias para la educación contable como se describe en la Tabla 3 (Lawson et al., 2014).

La competencia tecnológica incluye resultados como el conocimiento del modelado de hojas de cálculo; uso de tecnología para acceder a Big Data para análisis financieros; uso de tecnologías de comunicación, como visualización interactiva de datos; conocimiento del diseño de sistemas de información; conocimiento del propósito de los sistemas de información y Big Data, incluido el hardware y el software que les permiten funcionar; y problemas relacionados, como la seguridad informática y la continuidad del negocio (Lawson et al., 2014).

Rezaee \& Wang (2017) determinaron la necesidad de incorporar el tema de Big Data en el currículo de programas de contaduría pública en China, para la contabilidad forense, sobre todo para la detección de fraude. Del mismo modo, Sledgianowski et al. (2017) desarrollaron un enfoque que integra Big Data, sistemas de información y tecnologías, en el plan de estudios de contabilidad, proporcionando ejemplos para integrar sistemas de información y competencias tecnológicas con 
competencias contables basadas en la disciplina de cada asignatura. La Tabla 4 resume el enfoque propuesto.

Tabla 3. Integración de competencias para la educación contable

Table 3. Integration of competencies for accounting education

\begin{tabular}{lll}
\hline Competencias contables & Competencias fundamentales & Competencias de gestión \\
\hline Informes y análisis externos & Comunicación & Liderazgo \\
\hline Planeación, análisis y control & Cuantitativas & Ética \\
\hline $\begin{array}{l}\text { Impuestos, cumplimiento y } \\
\text { planificación }\end{array}$ & $\begin{array}{l}\text { Pensamiento analítico y solución de } \\
\text { problemas }\end{array}$ & $\begin{array}{l}\text { Procesos administrativos y de } \\
\text { mejoramiento }\end{array}$ \\
\hline Sistemas de información & Relaciones interpersonales & $\begin{array}{l}\text { Gobierno corporativo, riesgos y } \\
\text { cumplimiento }\end{array}$ \\
\hline Aseguramiento y control interno & Tecnología & Otras competencias de negocios \\
\hline
\end{tabular}

Tabla 4. Integración de estrategias de Big Data, sistemas de información y tecnología en los currículos de contaduría pública

Table 4. Integration of big data strategies, information systems, and technology into public accounting curricula

\begin{tabular}{|c|c|}
\hline Componente & Estrategia de integración \\
\hline \multirow{6}{*}{$\begin{array}{l}\text { Contabilidad } \\
\text { financiera }\end{array}$} & $\begin{array}{l}\text { Buscar volúmenes de datos financieros y registros de la compañía en diversos medios } \\
\text { electrónicos y analizarlos }\end{array}$ \\
\hline & $\begin{array}{l}\text { Calcular razones financieras y determinar las tendencias de las series de tiempo para o para } \\
\text { una industria determinada utilizando hojas de cálculo o herramientas de software estadístico }\end{array}$ \\
\hline & Uso de la hoja de cálculo (Excel) para registros contables \\
\hline & Manejo del lenguaje XBRL \\
\hline & Integración de los sistemas de información (ERP) para ingresar datos \\
\hline & $\begin{array}{l}\text { Big data, manejando diferentes volúmenes y variedad en una aplicación práctica, y } \\
\text { demostrar los conceptos contables aprendidos en clase aplicados al mundo real de las } \\
\text { compañías }\end{array}$ \\
\hline \multirow{5}{*}{$\begin{array}{l}\text { Gestión y } \\
\text { contabilidad de } \\
\text { costos }\end{array}$} & Análisis de negocios de datos estructurados y no estructurados en costos de adquisición \\
\hline & Análisis predictivo para evaluar situaciones hipotéticas \\
\hline & $\begin{array}{l}\text { Uso de hoja de cálculo y software para representar los datos gráficamente en un formato útil } \\
\text { para la toma de decisiones y la comunicación (visualización interactiva) }\end{array}$ \\
\hline & $\begin{array}{l}\text { Practicar el análisis predictivo usando métodos estadísticos y modelos de decisión usando } \\
\text { tecnología de hoja de cálculo capaz de programación lineal y simulación de Monte Carlo }\end{array}$ \\
\hline & $\begin{array}{l}\text { Uso de herramientas analíticas descriptivas y predictivas para desarrollar pronósticos de } \\
\text { presupuesto y realizar análisis de sensibilidad }\end{array}$ \\
\hline \multirow{4}{*}{ Auditoría } & $\begin{array}{l}\text { Uso de software para la creación de documentos de trabajo y la investigación de técnicas de } \\
\text { auditoría, así como la evaluación de los controles internos }\end{array}$ \\
\hline & Software de auditoría generalizado para consultar anomalías en los datos \\
\hline & Visualización de datos en auditoría \\
\hline & Aprender a identificar fraudes al consultar datos de transacciones \\
\hline \multirow{3}{*}{$\begin{array}{l}\text { Sistemas de } \\
\text { información } \\
\text { contable }\end{array}$} & $\begin{array}{l}\text { Integración de software gratuito para preparar diagramas de flujo de datos, diagramas de } \\
\text { flujo y estructura de base de datos }\end{array}$ \\
\hline & Software para administrar proyectos \\
\hline & Software para minería de procesos \\
\hline
\end{tabular}

\section{METODOLOGÍA}


La metodología aplicada consistió en explorar a través de datos secundarios los planes de estudio de 29 universidades para identificar la relación directa con el Big Data. La investigación se desarrolló a través de las siguientes actividades:

Marco referencial: se realizó búsquedas en bases de datos científicas con el criterio de búsqueda de 'Big data y Contabilidad'. El marco referencial se organizó en conceptos, Big Data y contabilidad y los referentes bibliográficos en cuanto a la incorporación de Big data, tecnología y sistemas de información en el currículo de contaduría pública.

Recolección de datos de los currículos de contaduría pública acreditados: se tomó el 100 \% de los programas de contaduría pública acreditados en Colombia, es decir, 29 programas. La información de los currículos y perfiles se extrajo directamente de las páginas web de las universidades.

Elaboración base de datos: se ingresaron todas las asignaturas de cada programa acreditado con el respectivo número de créditos. Adicionalmente, se clasificaron las asignaturas en grupos de componentes. Se tomaron los perfiles profesionales de cada programa para explorar si estos incorporan competencias de Big Data. Adicionalmente se seleccionó dos asignaturas (Informática y sistemas, y Estadística) para profundizar en el micro currículo que permitiera identificar temas o actividades relacionadas con Big Data.

Elaboración de informes: una vez tabulada toda la información, se desarrollaron informes para representar los principales resultados.

\section{RESULTADOS Y DISCUSIÓN}

En este apartado se relacionan los principales hallazgos de la relación del Big Data con los planes de estudio de las universidades. Entonces se consultó en el sistema del CNA las universidades acreditadas en Colombia, obteniendo un resultado de 29 instituciones acreditadas, tal como se detalla en la Figura 1.

La Figura 1 contiene información sobre la cantidad de programas de contaduría pública en Colombia. En términos globales, la figura muestra que las universidades acreditadas están ubicadas en mayor proporción en las ciudades de Bogotá con 9, Cali 6, Medellín 3 y Bucaramanga con 2; lo que representan un $25 \%$ del total de las 13 ciudades. En la Figura 2, se relaciona la cantidad de semestres por cada universidad, y al analizar la información, se puede apreciar que el $52 \%$ ofrece programas con una duración de 10 semestres; 38 \% con una duración de 9; y solo el $11 \%$ ofrece programas de 8 semestres. 


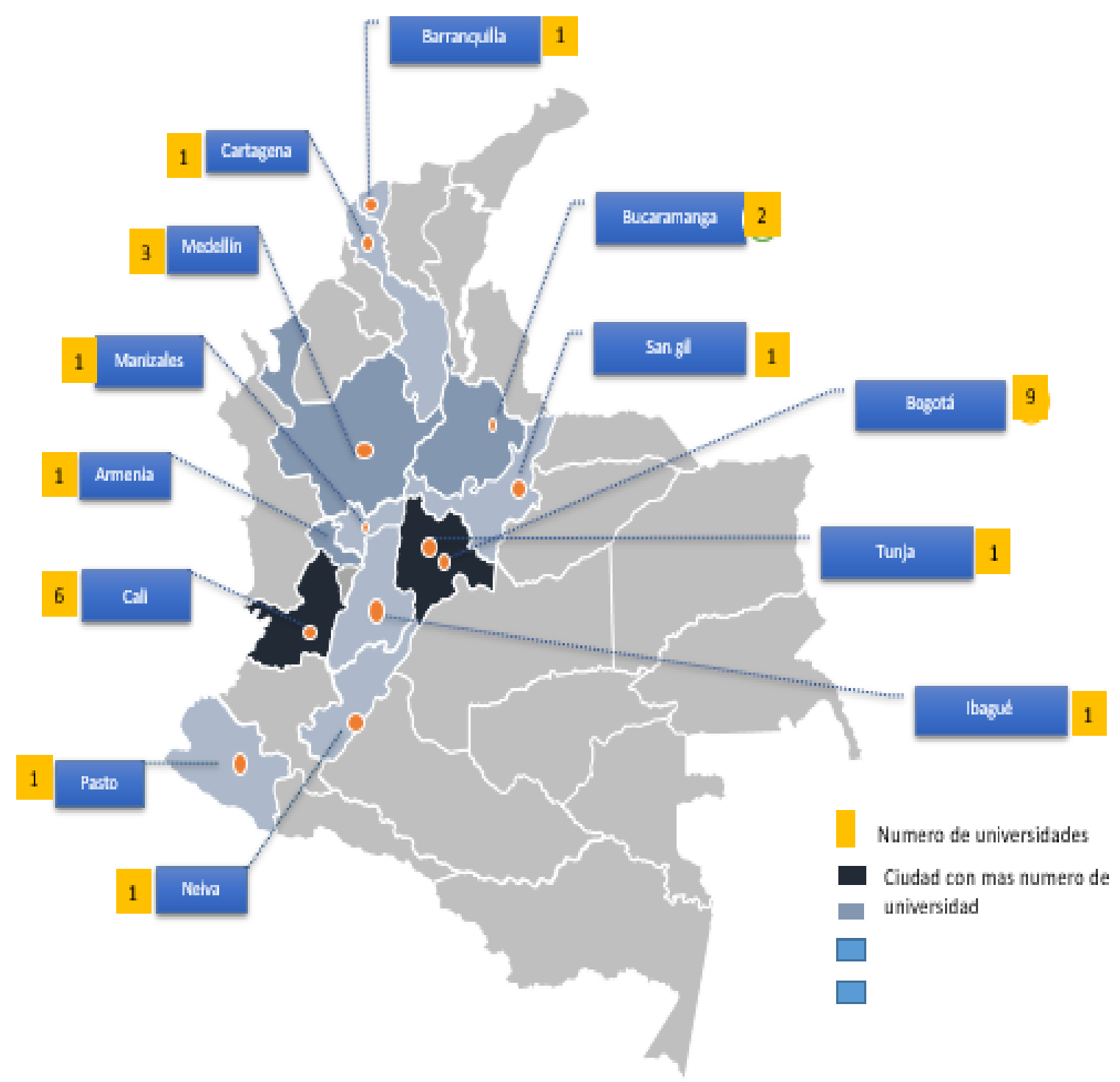

Figura 1. Programas de contaduría pública acreditados en Colombia por ciudad

Figure 1. Accredited public accounting programs in Colombian cities

Fuente: elaboración propia, tomado de las páginas web de las universidades.

Adicionalmente, se realiza la identificación de créditos académicos de las universidades; que según el Ministerio de Educación Superior (MinEducación, 2018): «Un crédito académico es la unidad que mide el tiempo estimado de actividad académica del estudiante en función de las competencias profesionales y académicas que se espera que el programa desarrolle». Ahora bien, el sistema educativo vela para que a través de los créditos académicos las instituciones garanticen las condiciones sociales y económicos de los profesionales en esta área. Frente a esto, en la Figura 3 se evidencia que, en Colombia, las universidades acreditadas ofrecen programas de contaduría pública con un promedio de 160 créditos, como se puede ver representado en línea naranja. 
Análisis de la integración del Big Data en los programas de contaduría pública en universidades acreditadas en Colombia

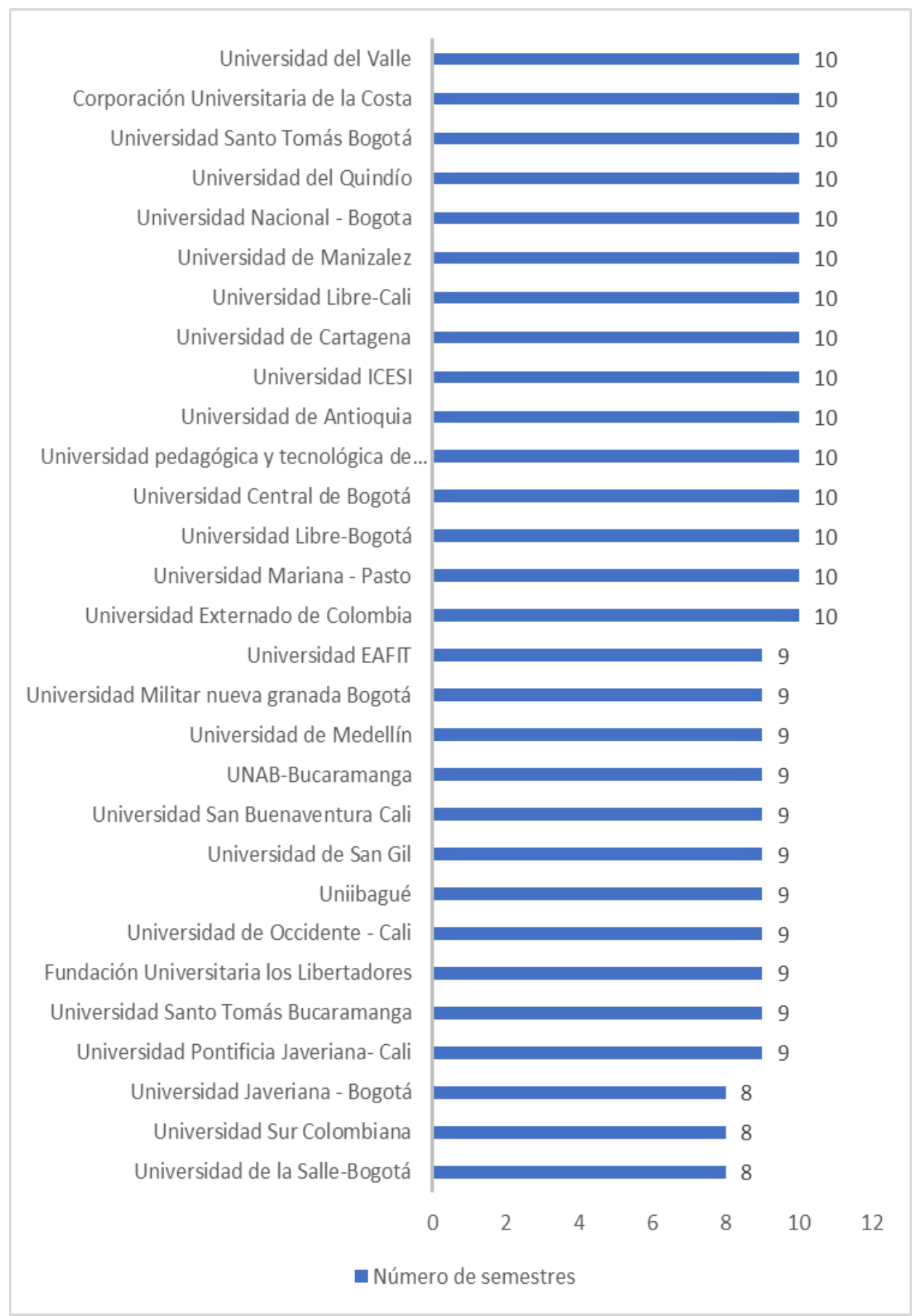

Figura 2. Cantidad de semestres por universidad

Figure 2. Number of terms by university

Fuente: elaboración propia con base a la malla curricular de las universidades. 


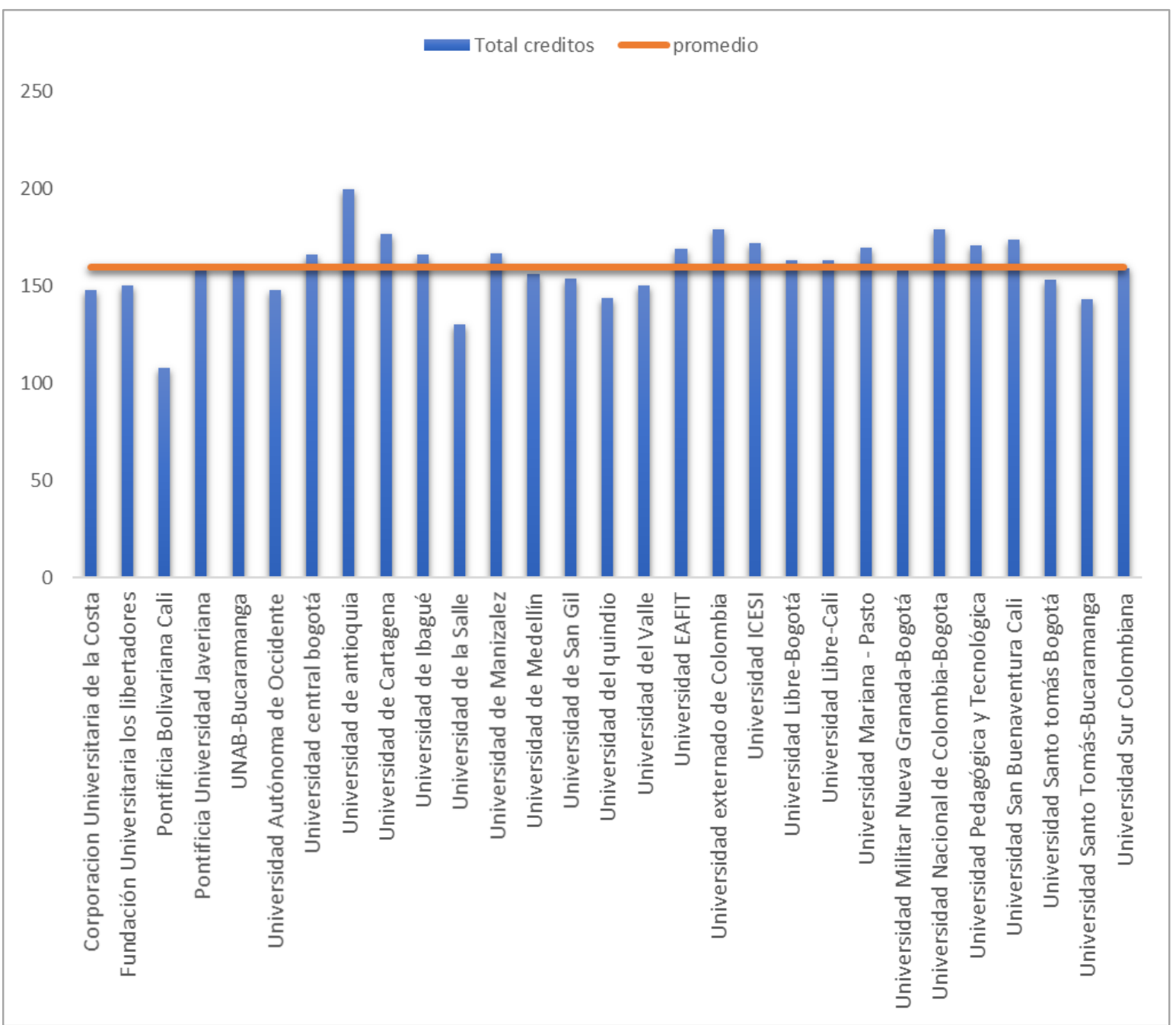

Figura 3. Promedio de créditos de las asignaturas

Figure 3. Average number of credits of the courses

Fuente: elaboración propia con base a la malla curricular de las universidades.

Sumado a lo anterior, se clasificaron las asignaturas de las 29 universidades en componentes genéricos, que permitieran agrupar todos los programas. Por tanto, en la Figura 4 se muestra la clasificación de las asignaturas en 19 componentes. 
Análisis de la integración del Big Data en los programas de contaduría pública en universidades acreditadas en Colombia

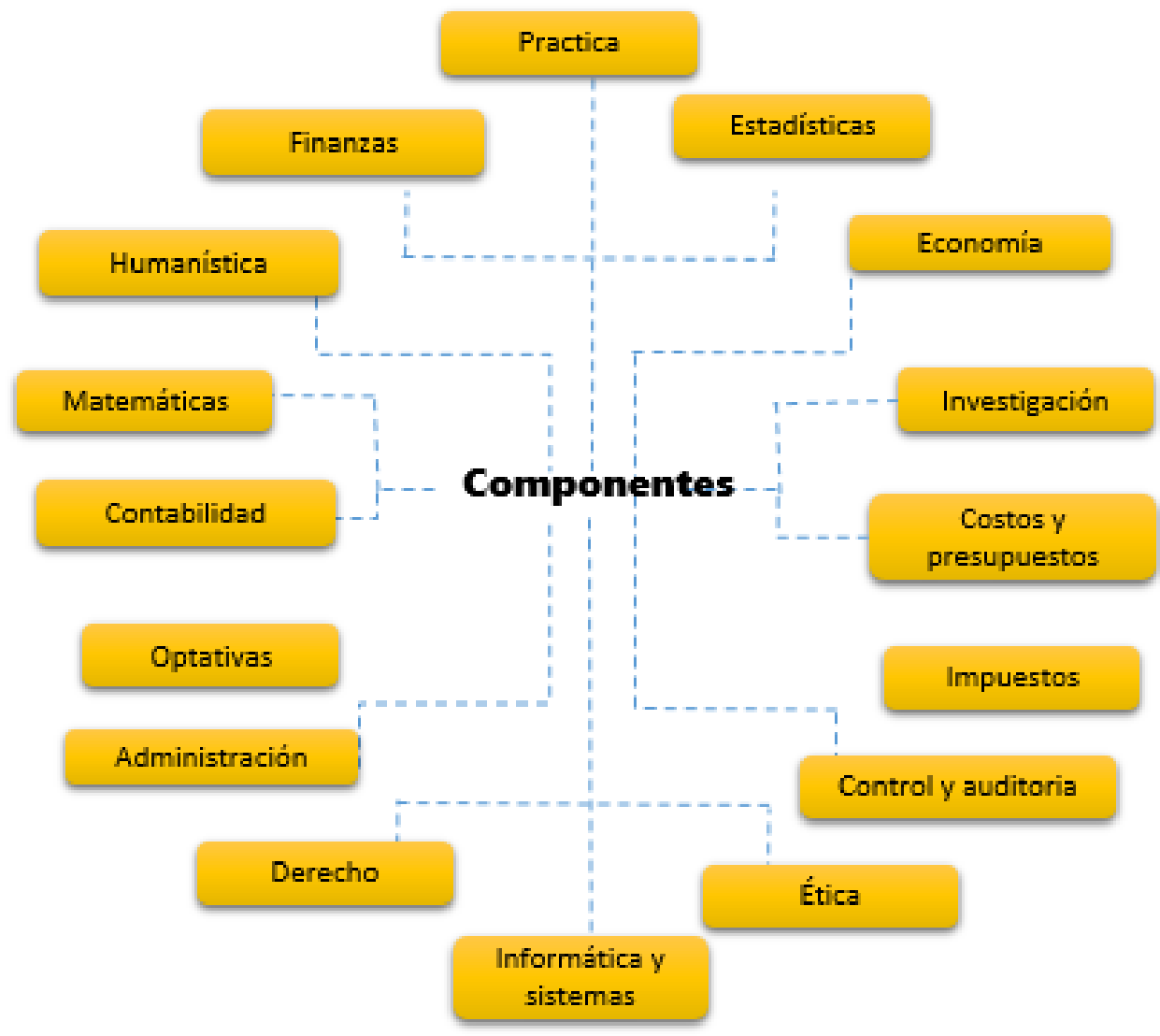

Figura 4. Grupos de asignaturas por componentes

Figure 4. Courses grouped by field

Fuente: elaboración propia con base a la malla curricular de las universidades.

Para identificar qué porcentaje de participación tiene cada uno de los componentes se hizo una validación de acuerdo con el número de créditos de las asignaturas. Estos datos, se pueden evidenciar en la Figura 5, que está representada con el nombre de cada componente y el porcentaje de uso comprendido entre $0 \%$ y $16 \%$. En términos generales, la figura indica que, el componente de mayor participación es el currículo de Contabilidad con un $13.55 \%$, seguido de los componentes de humanística y electivas con un porcentaje de $8.49 \%$ y $8.11 \%$. Adicionalmente, finanzas y economía con un porcentaje de $6.49 \%$, costos y presupuestos con un $6.30 \%$, control y auditoría con $3.24 \%$, derecho, administración e impuestos con un promedio de $5.5 \%$; y en menor proporción, con menos de $5 \%$, optativas, matemáticas, inglés, estadística, informática y sistemas, ética, práctica y proyectos. 


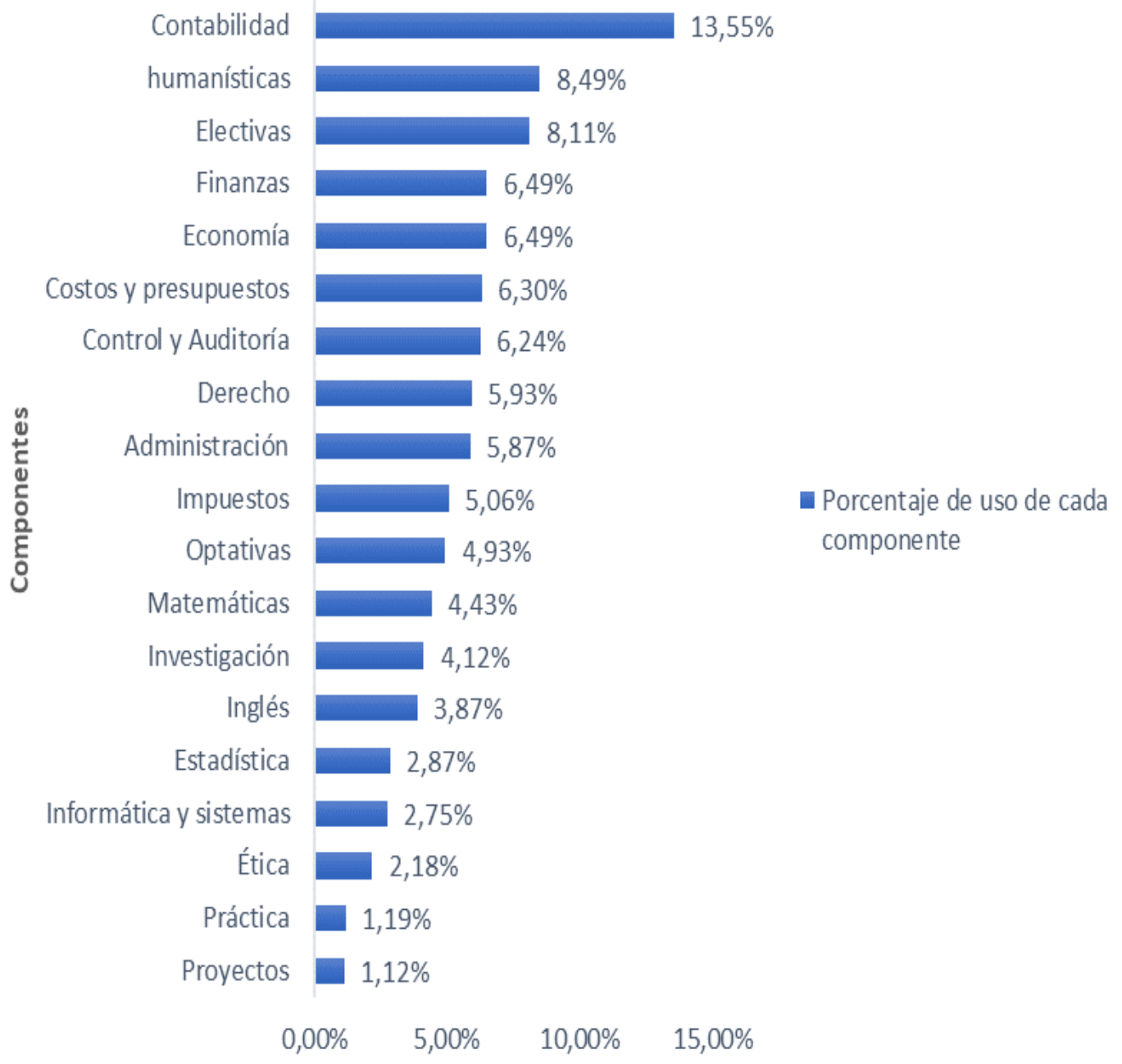

Figura 5. Porcentaje de asignaturas por componentes

Figure 5. Percentage of courses by field

Fuente: elaboración propia con base a la malla curricular de las universidades.

Por otro lado, se revisaron los perfiles ocupacionales y profesionales de cada uno de los 29 programas encontrando que ninguna menciona de manera directa el Big Data, tal como se puede ver en las Figuras 6 y 7 .

En la Figura 6 se relaciona los componentes asociados al perfil ocupacional que más enfatizaban las 29 universidades. Encontrando que son muchas las actividades que puede ejercer el profesional de contaduría pública: desde analizar información financiera, asesoramiento contable, tributario o de impuestos; hasta tener la capacidad de dirigir proyectos de inversión, planeación o diagnosticar unidades operativas en aspectos financieros. También hay un componente de tecnologías de información que apoyan el diseño de sistemas de información para toma de decisiones estratégicas. 
Análisis de la integración del Big Data en los programas de contaduría pública en universidades acreditadas en Colombia

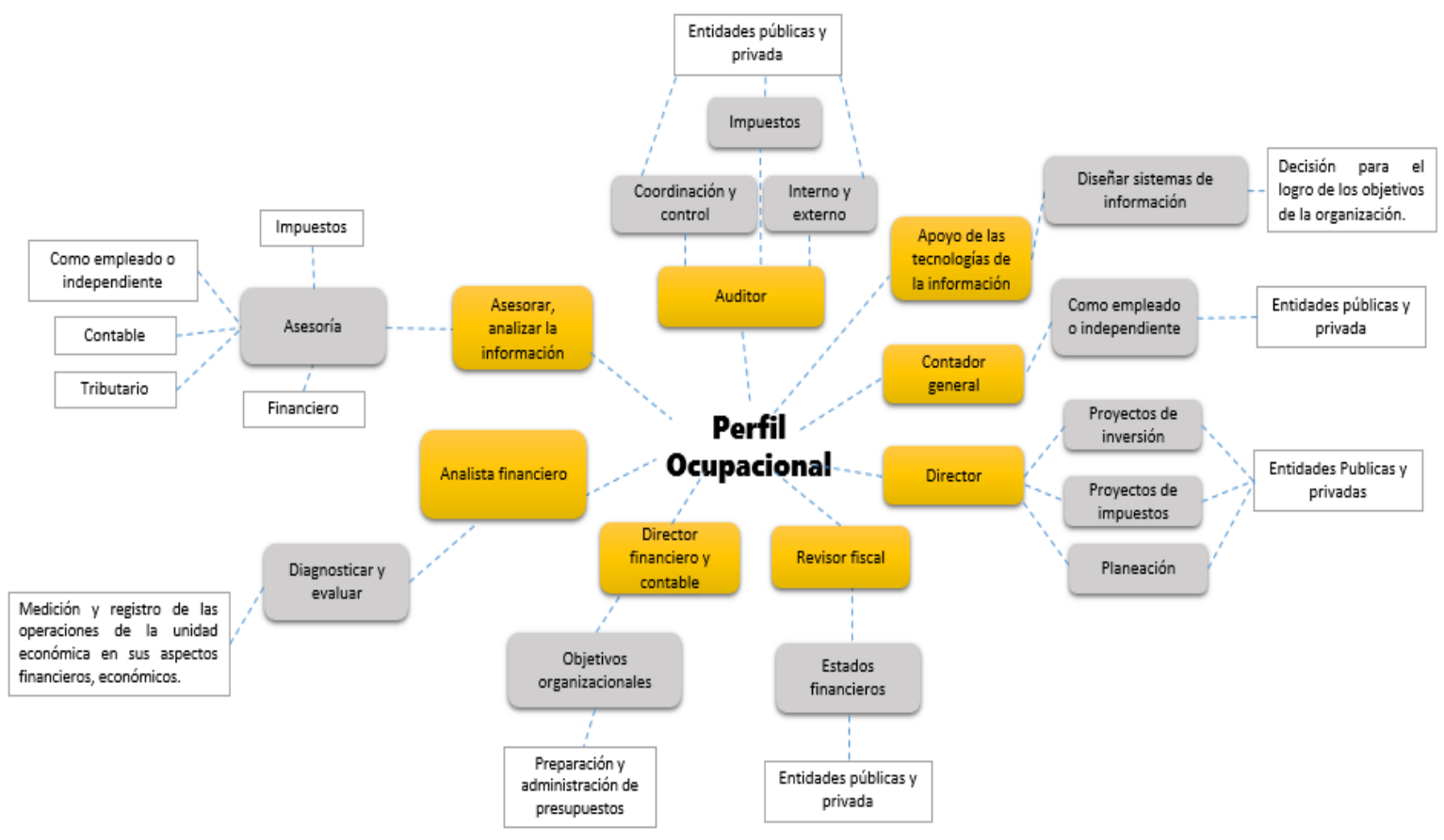

Figura 6. Perfil ocupacional

Figure 6. Job opportunities Fuente: elaboración propia.

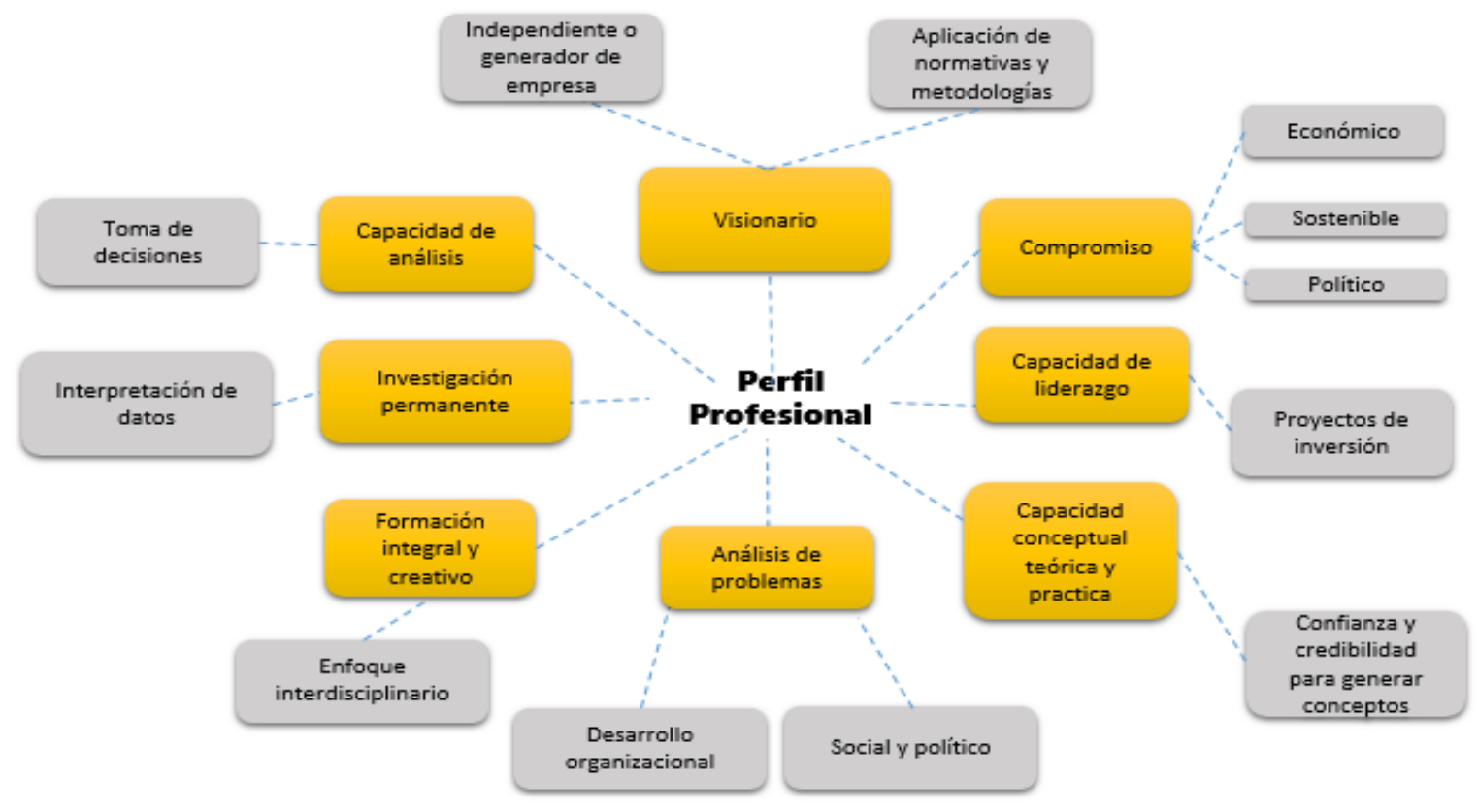

Figura 7. Perfil profesional

Figure 7. Graduate profile

Fuente: elaboración propia. 
Algunas universidades, de manera tangencial, incorporan las tecnologías de la información como una actividad clave en la gestión contable, como la Universidad de La Costa y la Universidad Libre, indicando que el perfil ocupacional se enfoca en formar profesionales con un perfil gerencial conocedor de las tecnologías de la información con responsabilidad social organizacional. Para la Universidad de Antioquia, el profesional tendrá las suficientes capacidades para asesorar y analizar información para la toma de decisiones. En cuanto a las Universidades de Ibagué, Universidad del Sur, Universidad Nacional, entre otras, están preparando profesionales para desempeñarse en organizaciones privadas y públicas, en los puestos de: contador general, contralor, director de finanzas, tesorero, gerente de impuestos o director de presupuestos; como empleado o de manera independiente.

La Figura 7 hace referencia a las capacidades del perfil profesional, haciendo referencia a la gestión eficiente y estratégica que toma la formación contable para transformar las empresas en agentes productivos. La mayoría coincide en las habilidades que deben desarrollarse para interactuar con otros profesionales bajo un entorno ético, comprometido en lo político, social y sostenible. También que se reconozca la gestión basada en confianza y credibilidad para tomar decisiones, como lo describe la universidad del Valle: «nuestros egresados son personas con una alta capacidad de decisión». La Universidad Javeriana comprende entre el perfil profesional, la capacidad de ejercer la profesión en todas las actividades relacionadas con el área contable y de finanzas.

La Universidad de San Gil lo relaciona con la aplicación de conocimientos para trabajar de forma independiente o como generador de empresa. La Universidad de Externado de Colombia manifiesta que el perfil profesional aportará a la alta gerencia en las organizaciones, por su visión y capacidad analítica y propositiva.

Por otro lado, se revisó en las asignaturas optativas de profundización que ofertan los programas, evidenciando que ninguno considera estos temas dentro de su línea de profundización. Sin embargo, por la relación que tiene el Big Data con los sistemas de información y la estadística, se enfatiza en ambos componentes como se ve en la Figura 4, desagregando el número de créditos por programa de los componentes de sistemas y estadística, como se ve en la Tabla 5.

Se nombran las 29 universidades relacionando el total de créditos de los componentes en informática y sistemas y estadística. Se evidencia que solo 20 universidades tienen incluidas la asignatura de Informática y Sistemas, es decir, el 61\%. En cuanto a la asignatura de Estadística, todas las universidades incluyen la materia en la malla curricular. Las universidades que mayor número de créditos tienen destinado para el componente de Informática y Sistemas son los programas de la Universidad Externado de Colombia, con 15 créditos, y la Corporación Universitaria de la Costa con 11. En cuanto a las asignaturas de Estadística, la Universidad ICESI es la que más créditos tiene, con 9, seguida de las Universidades Autónoma de Bucaramanga y Autónoma de Occidente, con 8 respectivamente. 
Análisis de la integración del Big Data en los programas de contaduría pública en universidades acreditadas en Colombia

Tabla 5. Número de créditos por programa relacionado con sistemas y estadística

Table 5. Number of credits related to information systems and statistics by program

\begin{tabular}{|c|c|c|}
\hline Universidad & $\begin{array}{l}\text { Informática y } \\
\text { sistemas }\end{array}$ & Estadística \\
\hline Corporación Universitaria de la Costa & 11 & 3 \\
\hline Fundación Universitaria Los Libertadores & & 6 \\
\hline Pontificia Bolivariana Cali & & 3 \\
\hline Pontificia Universidad Javeriana & 5 & 3 \\
\hline UNAB-Bucaramanga & & 8 \\
\hline Universidad Autónoma de Occidente & & 8 \\
\hline Universidad Central Bogotá & & 6 \\
\hline Universidad de Antioquia & 2 & 4 \\
\hline Universidad de Cartagena & 3 & 6 \\
\hline Universidad de Ibagué & & 4 \\
\hline Universidad de La Salle & & 4 \\
\hline Universidad de Manizales & 4 & 8 \\
\hline Universidad de Medellín & 3 & 3 \\
\hline Universidad de San Gil & 3 & 6 \\
\hline Universidad del Quindío & 7 & 2 \\
\hline Universidad del Valle & 8 & 6 \\
\hline Universidad EAFIT & 3 & 3 \\
\hline Universidad Externado de Colombia & 15 & 4 \\
\hline Universidad ICESI & 2 & 9 \\
\hline Universidad Libre-Bogotá & 6 & 6 \\
\hline Universidad Libre-Cali & 6 & 6 \\
\hline Universidad Mariana - Pasto & 7 & 3 \\
\hline Universidad Militar Nueva Granada-Bogotá & 2 & 6 \\
\hline Universidad Nacional de Colombia-Bogotá & 4 & \\
\hline Universidad Pedagógica y Tecnológica & 9 & 6 \\
\hline Universidad San Buenaventura Cali & & 7 \\
\hline Universidad Santo Tomás Bogotá & & 3 \\
\hline Universidad Santo Tomás-Bucaramanga & 6 & 5 \\
\hline Universidad Sur Colombiana & 7 & 6 \\
\hline
\end{tabular}

Fuente: elaboración propia.

Basado en lo anterior, se realiza un análisis del microcurrículo de las asignaturas Estadística e Informática y sistemas, de las 20 universidades, para mostrar las categorías que se relacionan en ellas. A partir de la Figura 8 se observa las categorías de la asignatura Informática y sistemas, donde se relacionan 5 componentes: Conceptualización, Creación y operación, Importancia y automatización de la información y Competencia profesional. Frente a esto, la mayoría de las universidades coinciden en que, esta asignatura debe ofrecer a los estudiantes los conocimientos teóricos básicos para el entendimiento de lo que representa un dato, información y conocimiento asociado a las competencias profesionales. Adicionalmente, la manipulación de software informático que se puedan aplicar a soluciones de problemas referidos al almacenamiento, tratamiento, presentación e intercambio de la información. 


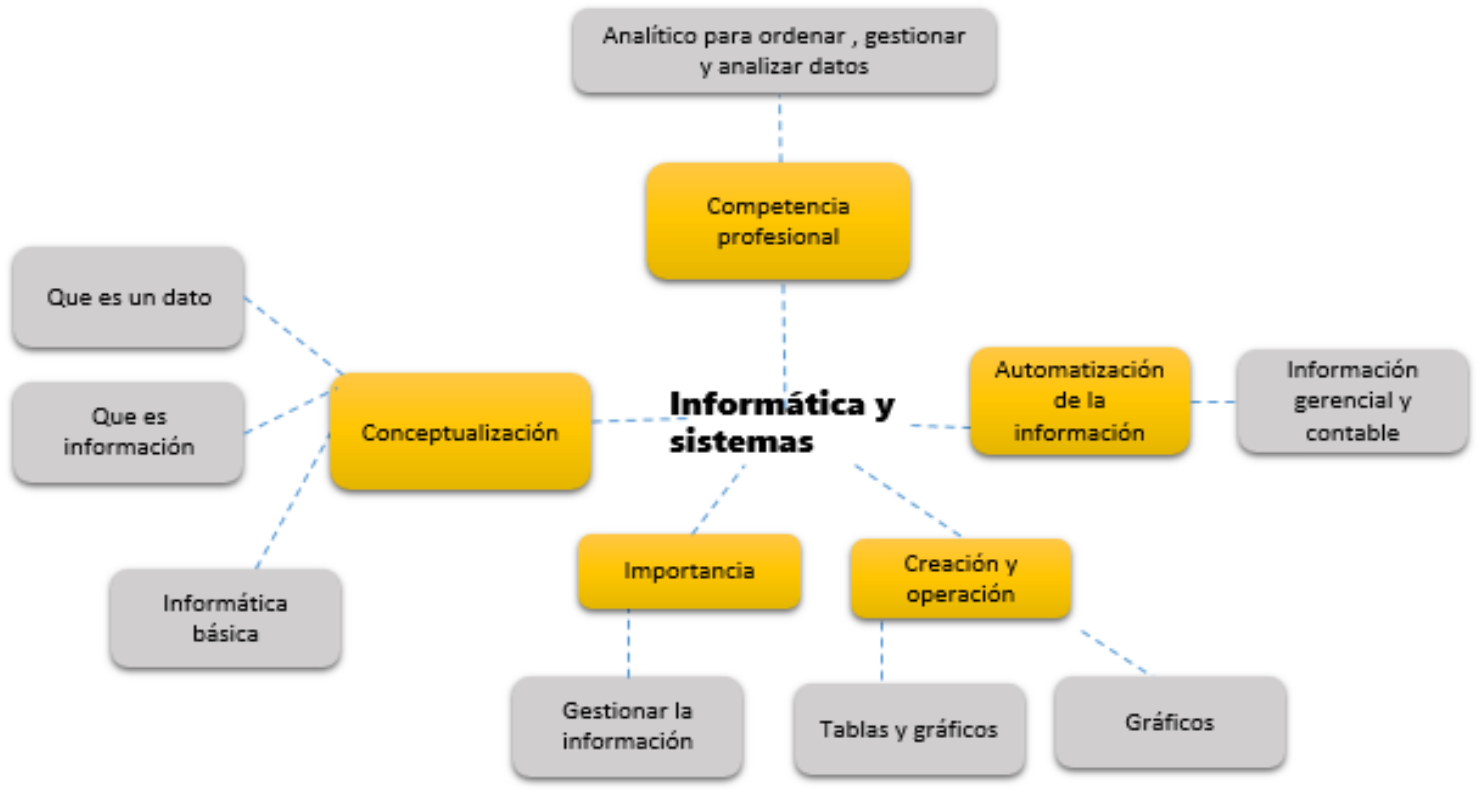

Figura 8. Informática y sistemas

Figure 8. Information systems

Fuente: elaboración propia.

En la competencia de automatización de la información corresponde a que los sistemas de información son cada vez más complejos y que requieren estructuración de los procesos para administrar la información de manera gerencial. Como es el caso de la Universidad Central de Cartagena, en el que justifica el perfil del profesional contable sobre la capacidad que deben tener para el análisis de variables económicas y sociales que permitan proveer a las empresas una visión holística para proyectar los escenarios a futuros. También, la Universidad de Medellín relaciona que los esfuerzos deben estar centrados en la formación de profesionales íntegros, con la capacidad de tomar decisiones.

Todo lo anterior significa que, más que las herramientas que se puedan enseñar en esta asignatura debe haber un pensamiento estratégico; es decir, tener la capacidad de trabajar con y contra lo incierto. Desde el punto de vista de Morin \& Pakman (1994), toda estrategia en cualquier dominio que sea tiene conciencia de apuesta, pero la noción de apuesta está en la conciencia del riesgo y de la incertidumbre; y lo que describe la literatura sobre la aplicación del Big Data, que más que un volumen de datos, lo que prima es el análisis y el pensamiento estratégico que se desarrollan para imaginar posibles escenarios que van con las decisiones estratégicas (Manyika et al., 2011). Así mismo, hacen referencia a la tendencia que esto representa para los avances de la tecnología que pueden medir y saber precisamente lo que está sucediendo en las empresas y traducirlas directamente en toma de decisiones (Goyzueta, 2015).

En la Figura 9, se presenta las competencias de la asignatura Estadística, de los 29 microcurrículos, en el que se relaciona: Introducción, Herramientas, Métodos, Regresión lineal. A partir de esto, las universidades coinciden en que el estudiante debe tener las habilidades y destrezas que faciliten la labor empresarial para la toma de decisiones. Considerando en el componente de Introducción, la 
identificación de la naturaleza de la estadística, su objetivo y el papel de importancia como disciplina que se puede aplicar en la industria y en la vida cotidiana.

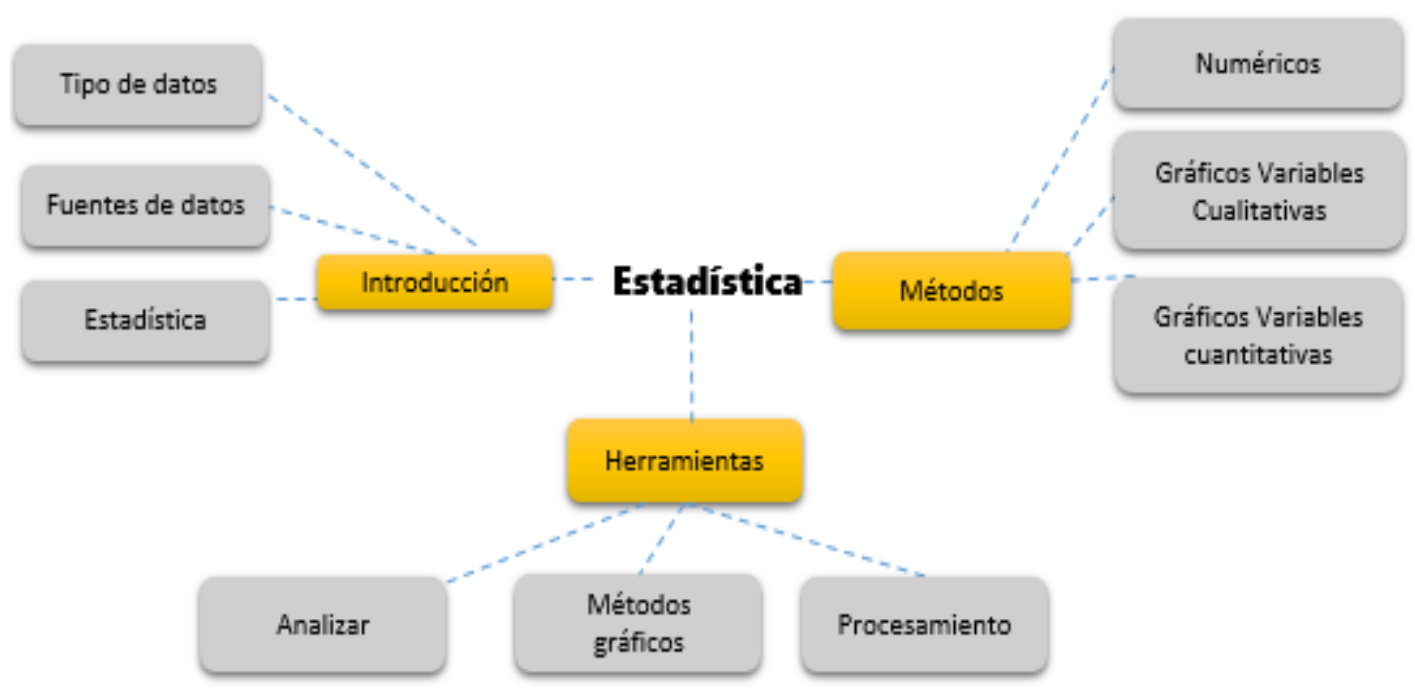

Figura 9. Estadística

Figure 9. Statistics

Fuente: elaboración propia.

También hay una relación en la competencia de Métodos, en términos de identificar la realidad a partir de los datos, es decir, aplicar diferentes procedimientos para el manejo de los datos cualitativos y cuantitativos, en vista de que suelen tener diferentes tamaños o intensidades. En cuanto la competencia de Herramientas, se puede identificar que las universidades están enfocadas en que el estudiante desarrolle las herramientas básicas que provee la estadística, para clasificar los datos obtenidos, procesarlos, analizarlos y describirlos para sacar conclusiones y presentar información.

\section{CONCLUSIONES}

El progreso activo de la generación de datos está provocando retos importantes, no solo para el área contable, sino a otras disciplinas. De tal manera que desarrollar habilidades en esta tecnología aporta a la innovación y progresos a la productividad y competitividad.

Frente a esto, los mercados y las empresas están viviendo una transformación de base tecnológica y social, creando oportunidades para los contadores y proporcionando nuevos enfoques para el espacio de divulgación tradicional de la información, incluso mediante la mejora de la información financiera en general, repensando ciertos aspectos de las auditorías y proporcionando a los inversores información transparente y directa.

Por tanto, las universidades colombianas han impulsado iniciativas normativas con el fin de ejercer un control sobre la calidad de la educación superior (Patiño \& Santos, 2009) y al revisar los currículos de los programas de contaduría pública, se evidencia que el Big Data no está incorporada de manera 
directa en los planes de estudio. Sin embargo, se ofrece una formación básica en las competencias de las asignaturas de Estadística e Informática y sistemas, que promueven los conocimientos de análisis de datos para procesarlos y transformarlos en decisiones estratégicas.

Por consiguiente, al desarrollarse habilidades para tomar decisiones estratégicas, se promueve en el profesional una destreza que se articula con lo que opina algunos autores, como Malvicino \& Yoguel (2016), quienes manifiestan que, si las empresas de todos los sectores promueven de manera eficiente tareas como la toma de decisiones, impactaría directamente en el aumento de la productividad y competitividad de las mismas.

Entonces se concluye que, aunque hay intención de formar estudiantes en estas habilidades, la participación de ambas asignaturas no tiene el peso suficiente dentro del plan de estudio, comparados con otras asignaturas, y tampoco se evidencian técnicas y herramientas que permitan procesar datos con formatos no estructurados. Frente a esto, las capacidades de los profesionales pueden ser limitadas si tenemos en cuenta la posición de Camargo-Vega, Camargo-Ortega, \& Joyanes-Aguilar (2015), cuando indican que: «hoy las compañías no saben qué hacer con el gran volumen de datos e información almacenada en diferentes medios o bases de datos, los cuales pueden ser de gran importancia, principalmente en la toma de decisiones».

Aunque los programas de Contaduría Pública en Colombia velan por tener una educación de calidad y cumplir con los estándares requeridos por la ley, los currículos aun necesitan articularse con las nuevas tendencias tecnológicas, que para este caso el Big Data. Es así como American Acounting Association (AAA, 2012) recomienda que para asegurar la educación de la contabilidad en el futuro es necesario que las universidades transformen el aprendizaje integrando en los currículos conocimiento de tecnologías que son tendencia o emergentes. Por lo tanto, es vital que desde los programas de Contaduría Pública incorporen estas competencias de manera intencionada.

Como trabajo futuro, se sugiere desarrollar instrumentos para evaluar, desde el punto de vista metodológico, si las competencias de Big Data, Tecnología y Sistemas de Información, se desarrollan de manera transversal en el plan de estudios.

\section{REFERENCIAS}

American Accounting Association (AAA). (2012). The Pathways Commission. Recuperado de: http://commons.aaahq.org/files/0b14318188/Pathways_Commission_Final_Report_Complete .pdf

Amani, F. A., \& Fadlalla, A. M. (2017). Data mining applications in accounting: A review of the literature and organizing framework. International Journal of Accounting Information Systems, 24, 32-58. https://doi.org/10.1016/j.accinf.2016.12.004

Appelbaum, D., Kogan, A., Vasarhelyi, M., \& Yan, Z. (2017). Impact of business analytics and enterprise systems on managerial accounting. International Journal of Accounting Information Systems, 25, 29-44. https://doi.org/10.1016/j.accinf.2017.03.003 
Assunção, M. D., Calheiros, R. N., Bianchi, S., Netto, M. A. S., \& Buyya, R. (2014). Big data computing and clouds: Trends and future directions. Journal of Parallel and Distributed Computing, 79, 315. https://doi.org/10.1016/j.jpdc.2014.08.003

Báez, H. A. (2015). La detección del fraude contable utilizando técnicas de minería de datos. Revista Publicando, 2(5), 103-113.

Camargo-Vega, J. J., Camargo-Ortega, J., \& Joyanes-Aguilar, L. (2015). Knowing the Big Data. Revista Facultad de Ingeniería (Universidad Pedagógica y Tecnológica de Colombia), 24(38), 63-77.

Chamorro-González, C. (2015). Investigación contable en los futuros contadores: elemento ontológico del desarrollo de la contabilidad verde. REDIELUZ. 5(1y2), 164-172. http://produccioncientificaluz.org/index.php/redieluz/article/view/21694/21489

Chang, F., Dean, J., Ghemawat, S., Hsieh, W., Wallach, D., Burrows, M. (2008). Bigtable: A Distributed Storage System for Structured Data. ACM Transactions on Computer Systems, 26(2).

Consejo Nacional de Acreditación. (2015). Lineamientos para la Acreditación Institucional. Retrieved from http://www.cna.gov.co/1741/articles-186359_Lin_Ins_2014.pdf

Federación Internacional de Contadores (IFAC). (2018). The Profession of the Digital Age: Accounting Engineering. Retrieved from http://www.ifac.org/global-knowledgegateway/technology/discussion/profession-digital-age-accounting-engineering

Financial Reporting Council (FRC). (2013). International Standard on Auditing (UK and Ireland). Recuperado de: https://www.frc.org.uk/getattachment/501de004-b616-43c3-8d65aeaebde19f8d/ISA-700-(UK-and-Ireland)-700-(Revised)-Independent-auditors-report-June2013.pdf

Gamage, P. (2016). Big Data: Are accounting educators ready? Accounting and Management Information Systems, 15(3), 588-604. https://doi.org/10.1016/j.jaccedu.2016.12.009

Gantz, J., \& Reinsel, D. (2012). The digital universe in 2020: Big Data, Bigger Digi tal Shadows, and Biggest Growth in the Far East. Idc, 2007(December 2012), 1-16.

Gartner. (2018). Big Data. Retrieved from https://www.gartner.com/it-glossary/big-data/

Gepp, A., Linnenluecke, M. K., O’Neill, T. J., \& Smith, T. (2018). Big data techniques in auditing research and practice: Current trends and future opportunities. Journal of Accounting Literature, 40, 102-115. https://doi.org/10.1016/j.acclit.2017.05.003

Goyzueta, S. I. (2015). Big Data marketing: una aproximación. Revista Perspectivas, (35), 147-158. https://doi.org/10.1117/12.780514

Huerta, E., \& Jensen, S. (2017). An Accounting Information Systems Perspective on Data Analytics and Big Data. Journal of Information Systems, 31(3), 101-114. https://doi.org/10.2308/isys-51799 
IDC \& Curto, J. (2012). Resumen Ejecutivo - Big Data: un mercado emergente. Recuperado de http://www.diarioabierto.es/wp-content/uploads/2012/06/Resumen-Ejecutivo-IDC-BigData.pdf

IFAC. (2018). International Federation of Accountants. Retrieved from http://www.ifac.org/

Janvrin, D. J., \& Watson, M. (2017). "Big Data": A new twist to accounting. Journal of Accounting Education, 38, 3-8. https://doi.org/10.1016/j.jaccedu.2016.12.009

Joyanes, L. (2013). Big data Análisis de grandes volúmenes de datos en organizaciones. (Alfaomega, Ed.) (Primera ed.). México.

Lawson, R. A., Blocher, E. J., Brewer, P. C., Cokins, G., Sorensen, J. E., Stout, D. E., Wouters, M. J. F. (2014). Focusing accounting curricula on students' long-run careers: Recommendations for an integrated competency-based framework for accounting education. Issues in Accounting Education, 29(2), 295-317. https://doi.org/10.2308/iace-50673

Malvicino, F., \& Yoguel, G. (2016). Big Data. Avances recientes a nivel internacional y perspectivas para el desarrollo local. Retrieved from www.ciecti.org.ar

Manyika, J., Chui, M., Brown, B., Bughin, J., Dobbs, R., Roxburgh, C., \& Byers, A. H. (2011). Big data: The next frontier for innovation, competition, and productivity. McKinsey Global Institute.

Martínez-Martínez, S., \& Lara-Navarra, P. (2014). El big data transforma la interpretación de los medios sociales. El profesional de la información, 23(6), 575-581. https://doi.org/10.3145/epi.2014.nov.03

Maté Jiménez, C. (2014). Big Data. Un nuevo paradigma de análisis de datos. Revista: Anales de Mecánica y Electricidad, 41(6), 10-16.

Mayer-Schomberger, V., \& Cukier, K., Iriarte, A. (trad) (2013). Big Data. La revolución de los datos masivos. Madrid: Houghton Mifflin Harcourt.

McKinsey \& Company. (2011). Big data: The next frontier for innovation, competition, and productivity. McKinsey Global Institute, 156. https://doi.org/10.1080/01443610903114527

MinEducación. (2018). Sistema de Créditos Académicos. Retrieved from https://www.mineducacion.gov.co/1621/article-87727.html

Ministerio de Educación Nacional. (2003). Resolución No. 3459 de 2003, 1-5.

Molina, L. C. (2002). Data mining: torturando a los datos hasta que confiesen. Fuoc, 1-11.

Morin, E. \& Pakman, M. (1994). Introducción al pensamiento complejo. Barcelona: Gedisa. 
Análisis de la integración del Big Data en los programas de contaduría pública en universidades acreditadas en Colombia

O’Brien, T. (2015). "Accounting" for Data Quality in Enterprise Systems. Procedia Computer Science, 64, 442-449. https://doi.org/10.1016/j.procs.2015.08.539

Patiño, R. A., \& Santos, G. (2009). La investigacion formativa en los programas de Contaduría Pública, caso Colombia. Review Literature and Arts of the Americas, 7, 23-34.

Puyol, J. (2014). Una aproximación a Big Data. Revista de Derecho UNED, (14), 471-506. https://doi.org/10.5944/RDUNED.14.2014.13303

Rezaee, Z., \& Wang, J. (2017). Relevance of Big Data to Forensic Accounting Practice and Education: Insight from China. 7th Annual International Conference on Accounting and Finance, (Af), 103110.

Saggi, M. K., \& Jain, S. (2018). A survey towards an integration of big data analytics to big insights for value-creation. Information Processing and Management, (December, 2016), 1-33. https://doi.org/10.1016/j.ipm.2018.01.010

Sáinz, M., Iñigo, M., Raquel, M., \& Sanz, M. (2013). El control de la reputación online para prevenir y gestionar una crisis. Telos Análisis, 95. Recuperado de: https://telos.fundaciontelefonica.com/archivo/numero095/el-control-de-la-reputacion-online-para-prevenir-y-gestionar-una-crisis/

Sledgianowski, D., Gomaa, M., \& Tan, C. (2017). Toward integration of Big Data, technology and information systems competencies into the accounting curriculum. Journal of Accounting Education, 38, 81-93. https://doi.org/10.1016/j.jaccedu.2016.12.008

Strong, C., Fodor, M., Cerwin, M., José Camargo-Vega, J., Felipe Camargo-Ortega, J., Joyanes-Aguilar, L., ... Gartner. (2015). Conociendo Big Data. Revista Facultad de Ingeniería (Fac. Ing.), eneroabril, 24(38), 22. https://doi.org/10.15517/eci.v6i1.19005

The association of Accountants and financial Professionals in Business (ACCA). (2012). 100 Drivers of Change for the Global Accountancy Profession.

The Association of Chartered Certified Accountants. (2013). Big Data: its power and perils, 1-40. Recuperado de: https://www.accaglobal.com/bigdata

Vasarhelyi, M. A., Kogan, A., \& Tuttle, B. M. (2015). Big data in accounting: An overview. Accounting Horizons, 29(2), 381-396. https://doi.org/10.2308/acch-51071

Warren, J. D., Moffitt, K. C., \& Byrnes, P. (2015). How big data will change accounting. Accounting Horizons, 29(2), 397-407. https://doi.org/10.2308/acch-51069 